\title{
PYROLYSIS CHARACTERISTICS OF HUADIAN OIL SHALES
}

\author{
WANG QING*, SUN BAIZHONG, HU AIJUAN, \\ BAI JINGRU, LI SHAOHUA
}

Northeast Dianli University

Jilin 132012 China

\begin{abstract}
Three oil shale samples from different areas in Huadian have been non-isothermally pyrolysed using thermogravimetric analyzer (TGA). The analyses were performed at different heating rates $\left(10,20,40,50,100 \mathrm{~K} \mathrm{~min}^{-1}\right)$ up to $900{ }^{\circ} \mathrm{C}$ with nitrogen as purge gas. The weight loss curve showed that pyrolysis of oil shale took place mainly in the range of $200-600{ }^{\circ} \mathrm{C}$. It was attributed to decomposition of hydrocarbonaceous material. At higher temperatures, the weight lessens due to decomposition of carbonates. On the basis of experimental data a model of pyrolysis kinetics was proposed. Kinetic parameters - activation energy $(E)$ and frequency factor $(A)$ - were determined by two methods: the direct Arrhenius plot method and the integral method. There was no clear relationship between activation energy and heating rate. The integral method of analysis gave lower values of activation energy than the direct Arrhenius plot method.
\end{abstract}

\section{Introduction}

The world reserves of conventional fossil fuels such as petroleum, natural gas and coal are finite. The supply of energy has become a worldwide problem in recent decades. Many countries have attempted to diversify their potential energy sources in order to cope with oil price increases and their effect on the economy. So, there are a plenty of researches into alternative sources of conventional fossil fuels. Oil shale represents an enormous potential as a substitute.

Oil shales contain organic matter, in the form of kerogen, which is defined as this fraction of the organic matter in a sedimentary rock that is insoluble in common petroleum solvents. The other fraction called bitumen is soluble in organic solvents, but its amount in the organic matter of oil shale is small [1]. Oil shale can be exploited to produce oil and gas by pyrolysis and electricity by direct combustion [2]. China is one of the countries in the world where oil

*Corresponding author: e-mail rlx888@126.com 
shale resources are great, and shale is suitable for large-scale exploitation and comprehensive utilization. China's deposits are distributed mainly in Maoming, Huadian and Fushun, Longkou, etc. [3]. Oil shale in Huadian deposit is of high grade and suitable for comprehensive exploration which includes oil shale mining, retorting, semi-coke combustion and production of building materials [4].

Thermogravimetric analysis (TGA) of oil shale samples has been extensively used as a means of determining pyrolysis characteristics. TGA may be carried out in isothermal or non-isothermal conditions, the latter being used more and more as it has several advantages over the isothermal method. First, experimental time is shorter. Second, the errors due to the thermal induction period are eliminated. Third, it simulates more closely the conditions expected at large-scale oil-shale retorting processes. So, many researchers around the world have used non-isothermal TGA technique to study the decomposition process and decomposition kinetics of oil shale.

The present investigation is an experimental study on three Huadian oil shale samples using a TGA apparatus under non-isothermal conditions. The experimental data were analysed to determine kinetic parameters - activation energy and frequency factor.

\section{Experimental}

In this research, all thermal experiments were conducted at atmospheric pressure using Perkin Elmer Pyris 1 Thermal Analyser, with $\mathrm{N}_{2}$ (supplied at a constant rate of $80 \mathrm{ml} \cdot \mathrm{min}^{-1}$ in normal conditions) as the purge gas. TG/DTG enables to measure mass loss as a function of temperature and (or) time. Experiments were performed at five heating rates (10, 20, 40, 50 and $100 \mathrm{~K} \cdot \mathrm{min}^{-1}$ ) over the temperature range of $20-900{ }^{\circ} \mathrm{C}$.

The investigations were performed on three oil shale samples S1, S2 and S3 taken from the 4th, 5th and 6th layers of Gonghe mines in Huadian, respectively. The samples used in the experiments weighed $10 \mathrm{mg}$, particle size was $0.2 \mathrm{~mm}$. Table 1 shows the data on proximate and ultimate analysis of oil shale samples. One can see that Huadian oil shale is a low-grade fuel with high content of ash and volatiles. This shale is unsuitable for longdistance transport, suiting for utilization near the site of discovery.

Table 1. Proximate and ultimate analysis of oil shales, \%

\begin{tabular}{|c|c|c|c|c|c|c|c|c|c|c|}
\hline \multirow{3}{*}{ Sample } & \multicolumn{5}{|c|}{ Proximate analysis } & \multicolumn{5}{c|}{ Ultimate analysis } \\
\cline { 2 - 11 } & $\mathrm{M}_{\mathrm{ad}}$ & $\mathrm{V}_{\mathrm{ad}}$ & $\mathrm{A}_{\mathrm{ad}}$ & $\mathrm{FC}_{\mathrm{ad}}$ & $\begin{array}{l}\mathrm{Q}_{\text {net,ar }}, \\
\mathrm{kJ} / \mathrm{kg}\end{array}$ & $\mathrm{C}_{\mathrm{ad}}$ & $\mathrm{H}_{\mathrm{ad}}$ & $\mathrm{N}_{\mathrm{ad}}$ & $\mathrm{O}_{\mathrm{ad}}$ & $\mathrm{S}_{\mathrm{ad}}$ \\
\hline $\mathrm{S} 1$ & 5.31 & 29.76 & 60.27 & 4.66 & 9319.70 & 23.68 & 3.96 & 0.59 & 10.67 & 0.83 \\
$\mathrm{~S} 2$ & 5.52 & 26.96 & 65.45 & 2.07 & 5922.72 & 17.69 & 2.48 & 0.39 & 13.41 & 0.58 \\
$\mathrm{~S} 3$ & 5.22 & 24.31 & 69.49 & 0.98 & 4396.23 & 13.90 & 1.73 & 0.39 & 13.95 & 0.54 \\
\hline
\end{tabular}




\section{Results and discussion}

Figures 1-3 show the weight loss (TG) and differential weight loss (DTG) curves of three oil shale samples S1, S2, and S3 in relation to heating rate to the final temperature of $900{ }^{\circ} \mathrm{C}$. Three samples exhibited similar patterns of thermal decomposition with increasing temperature. The curves demonstrate three stages in the mass-loss profile illustrated in the derivative curves.

Weight loss in the low-temperature region, from ambient up to approximately $200{ }^{\circ} \mathrm{C}$, has been attributed to the loss of moisture, interlayer water from clay minerals and also to decomposition of mineral nahcolite $\left(\mathrm{NaHCO}_{3}\right)$ which is one of the minerals present in the raw shale. Clay minerals present in oil shale may release structure water over a wide range of temperature up to about $550{ }^{\circ} \mathrm{C}$ [5], physical changes, such as softening and molecular rearrangement associated with the release of gases in kerogen

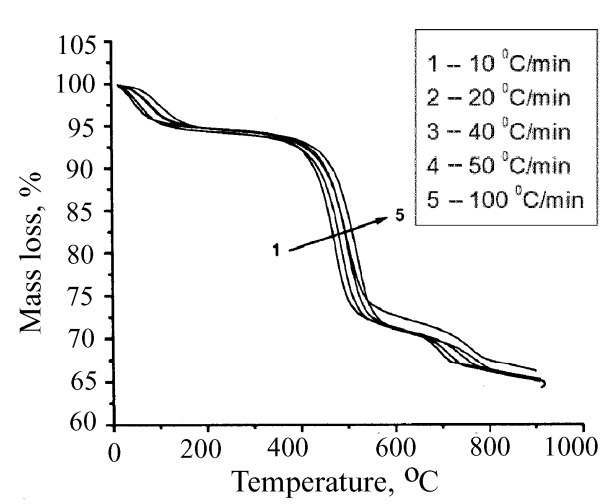

TG curves

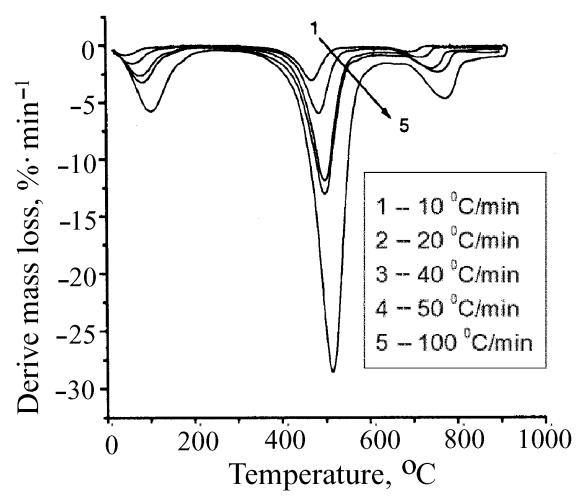

DTG curves

Fig. 1. Non-isothermal TG and DTG curves of the sample S1 at various heating rates.

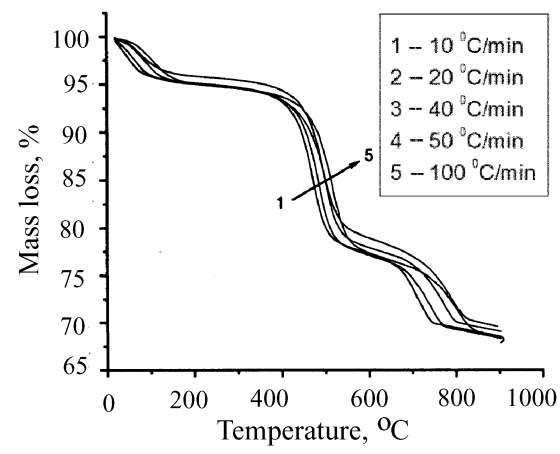

TG curves

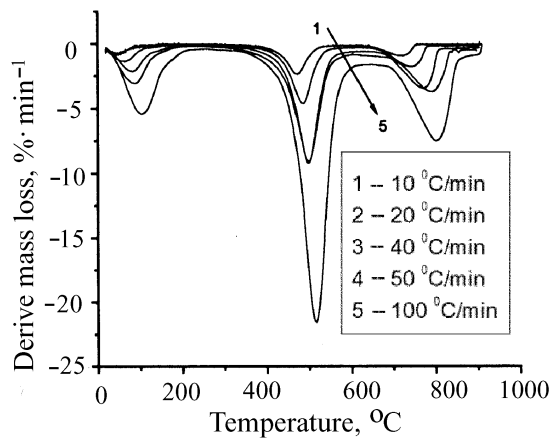

DTG curves

Fig.2. Non-isothermal TG and DTG curves of the sample S2 at various heating rates. 


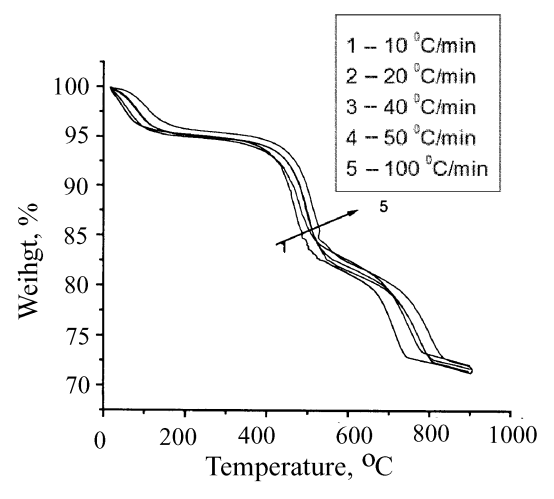

TG curves

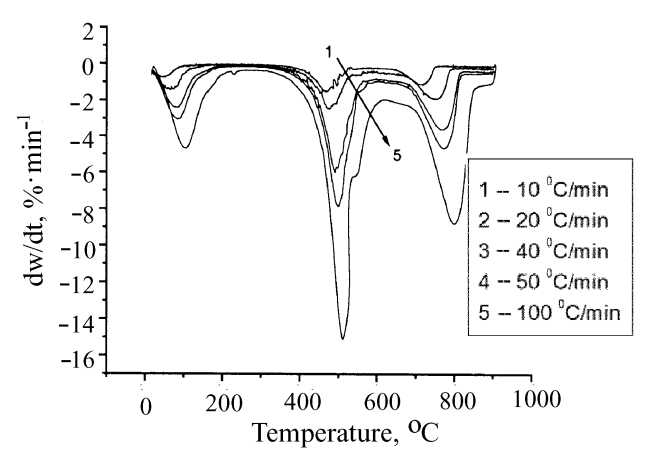

DTG curves

Fig.3. Non-isothermal TG and DTG curves of the sample S3 at various heating rates.

prior to its decomposition to bitumen may occur as well [6]. Above all, in this stage the predominant cause of mass loss is simply moisture. Usually, the weight loss in this stage is considered the measure of water present in oil shale.

The weight loss in the region from about 200 to $600{ }^{\circ} \mathrm{C}$ occurs on account of the hydrocarbonaceous material. Below $350{ }^{\circ} \mathrm{C}$ the weight loss is small, the weight loss curves are mostly horizontal. The main weight loss begins about $350{ }^{\circ} \mathrm{C}$, from then on, the rate of weight loss increases rapidly attributed to formation of volatile hydrocarbons. In this work, the three Huadian oil shale samples exhibit an one-stage thermal decomposition in the main weight loss area, similarly to Pakistan (Kark, Dharangi and Malgeen) [7] and Jordanian [8] oil shales. However, Turkish [9] and Moroccon [10] oil shales exhibit two-stage thermal decomposition. Therefore, weather the decomposition is an one-stage or two-stage process, depends on the type of oil shale. Usually, decomposition of kerogen to oil, gas and char products is a two-stage process. First, decomposition of kerogen to pyrolytic bitumen occurs and, second, decomposition of bitumen to final products takes place. Though the curves show one-stage or two-stage decomposition process of oil shales, the actual mechanism of decomposition is a much more complex reaction involving a series of parallel reactions [11].

In the third stage, between $600{ }^{\circ} \mathrm{C}$ and $900{ }^{\circ} \mathrm{C}$, the weight loss is attributed to decomposition of carbonate minerals such as calcite, dolomite, ankerite, and others. At the same time, $\mathrm{CO}_{2}$ (the product of carbonate decomposition) which at high temperature reacts with residual char to form $\mathrm{CO}$ also causes some weight loss. In this stage, the rate of weight loss is distinctly lower than that in the second stage.

Table 2 shows the data of weight loss in the three temperature ranges discussed above as shown in Figs. 1-3. The table emphasises the main weight loss due to decomposition of hydrocarbonaceous material at the second stage. 
Table 2. Weight loss of oil shales in relation to temperature range for various heating rates

\begin{tabular}{|c|c|c|c|c|c|}
\hline \multirow{2}{*}{ Sample } & \multirow{2}{*}{$\begin{array}{l}\text { Heating rate, } \\
\mathrm{K} \cdot \mathrm{min}^{-1}\end{array}$} & \multicolumn{3}{|c|}{ Mass loss (wt.\%) } & \multirow{2}{*}{$\begin{array}{l}\text { Total, } \\
\text { wt. } \%\end{array}$} \\
\hline & & $25-200{ }^{\circ} \mathrm{C}$ & $200-600{ }^{\circ} \mathrm{C}$ & $600-900{ }^{\circ} \mathrm{C}$ & \\
\hline \multirow{5}{*}{ S1 } & 10 & 5.3 & 23.8 & 4.8 & 34.9 \\
\hline & 20 & 5.7 & 23.6 & 5.7 & 35.0 \\
\hline & 40 & 5.3 & 23.5 & 5.9 & 34.7 \\
\hline & 50 & 5.2 & 22.1 & 6.5 & 33.8 \\
\hline & 100 & 5.3 & 23.6 & 6.9 & 35.8 \\
\hline \multirow{5}{*}{$\mathrm{S} 2$} & 10 & $\overline{4} . \overline{8}$ & 23 & 3.8 & $3 \overline{1} .6$ \\
\hline & 20 & 4.8 & 18.1 & 8.7 & 31.6 \\
\hline & 40 & 4.1 & 18 & 8.8 & 30.9 \\
\hline & 50 & 5.0 & 16.1 & 9.3 & 30.4 \\
\hline & 100 & 5.0 & 17.6 & 9.5 & 32.1 \\
\hline & 10 & $\overline{4} . \overline{7}$ & 14.1 & 9.9 & $2 \overline{8} . \overline{7}$ \\
\hline \multirow{4}{*}{ S3 } & 20 & 5.1 & 12.3 & 10.5 & 27.9 \\
\hline & 40 & 4.8 & 13.3 & 10.1 & 28.2 \\
\hline & 50 & 4.8 & 13.7 & 10 & 28.5 \\
\hline & 100 & 4.2 & 13.5 & 10.9 & 28.6 \\
\hline
\end{tabular}

Four temperatures characteristic of decomposition are defined: temperature of the onset of decomposition ( $\mathrm{T}_{\text {onset }}$ ), maximum decomposition temperature $\left(\mathrm{T}_{\max 1}\right)$, temperature of the end of decomposition of hydrocarbons $\left(\mathrm{T}_{\text {stop }}\right)$, and temperature of maximum decomposition of carbonate minerals $\left(\mathrm{T}_{\max 2}\right)$. Define $\Delta \mathrm{T}_{1 / 2}$ as the corresponding temperature zone of $\mathrm{dw} / \mathrm{dt}=1 / 2(\mathrm{dw} / \mathrm{dt})_{\max }$, which describes the concentrative degree of volatile material evolved. Table 3 gives the particular TGA data in relation to heating rate in the temperature range of $200-900{ }^{\circ} \mathrm{C}$. Figure 4 defines the symbols used in Table 3. Table 3 shows that as the heating rate is increased, $T_{\text {onset }}, T_{\max 1}$, $\mathrm{T}_{\max 2}$ and $\mathrm{T}_{\text {stop }}$ increased as well. The DTG peak, which is a measure of relative reactivity (defined as the ratio of the rate of weight loss per unit of time), shifts to higher temperature. It is caused by the variation of the rate of heat transfer with the change in the heating rate and the short exposure time to a certain temperature at a higher heating rate, as well as the kinetics of decomposition. Heating rate also affects the weight loss at a certain temperature. For example, at the same temperature, the lower the heating rate, the more the volatile material evolved. It is not clear how the heating rate affects overall weight loss, but it obviously shortens the time of decomposition, advances the rate of weight loss. Figure 5 clearly demonstrates the relationship. 
Table 3. Comparison of thermogravimetric data of oil shale samples

\begin{tabular}{|c|c|c|c|c|c|c|c|c|}
\hline \multirow[t]{2}{*}{ Sample } & \multirow{2}{*}{$\begin{array}{l}\text { Heating } \\
\text { rate, } \\
\mathrm{K} \cdot \mathrm{min}^{-1}\end{array}$} & \multicolumn{4}{|c|}{ Temperature, ${ }^{\circ} \mathrm{C}$} & \multicolumn{2}{|c|}{$\begin{array}{c}\text { Rate of weight } \\
\text { loss, } \\
\text { wt. } \% \cdot \min ^{-1}\end{array}$} & \multirow[t]{2}{*}{$\begin{array}{c}\Delta \mathrm{T}_{1 / 2}, \\
{ }^{\circ} \mathrm{C}\end{array}$} \\
\hline & & $\mathrm{T}_{\text {onset }}$ & $\mathrm{T}_{\max 1}$ & $\mathrm{~T}_{\max 2}$ & $\mathrm{~T}_{\text {stop }}$ & $R 1$ & $R 2$ & \\
\hline \multirow{5}{*}{ S1 } & 10 & 424 & 471 & 506 & 695 & -3.62 & -0.5 & 47 \\
\hline & 20 & 442 & 486 & 516 & 715 & -5.93 & -1.06 & 59 \\
\hline & 40 & 454 & 498 & 530 & 746 & -11.92 & -2.03 & 62 \\
\hline & 50 & 450 & 498 & 530 & 758 & -13.06 & -2.34 & 65 \\
\hline & 100 & 465 & 516 & 552 & 773 & -28.55 & -4.68 & 66 \\
\hline \multirow{5}{*}{$\mathrm{S} 2$} & 10 & $\overline{4} 3 \overline{3}$ & $\overline{4} \overline{4}$ & 498 & 722 & -2.34 & -0.94 & 55 \\
\hline & 20 & 442 & 487 & 515 & 740 & -4.61 & -1.82 & 57 \\
\hline & 40 & 456 & 499 & 526 & 769 & -9.22 & -3.47 & 59 \\
\hline & 50 & 450 & 499 & 536 & 789 & -9.11 & -3.72 & 67 \\
\hline & 100 & 466 & 519 & 562 & 801 & -21.55 & -7.53 & 65 \\
\hline \multirow{5}{*}{ S3 } & 10 & $\overline{4} \overline{1} \overline{1}$ & $\overline{4} \overline{1}$ & $52 \overline{3}$ & $7 \overline{17}$ & -1.51 & -1.11 & 75 \\
\hline & 20 & 437 & 477 & 524 & 753 & -2.46 & -1.89 & 66 \\
\hline & 40 & 455 & 491 & 527 & 771 & -5.97 & -3.58 & 65 \\
\hline & 50 & 456 & 498 & 541 & 772 & -7.82 & -4.65 & 68 \\
\hline & 100 & 458 & 512 & 548 & 799 & -15.06 & -8.78 & 50 \\
\hline
\end{tabular}

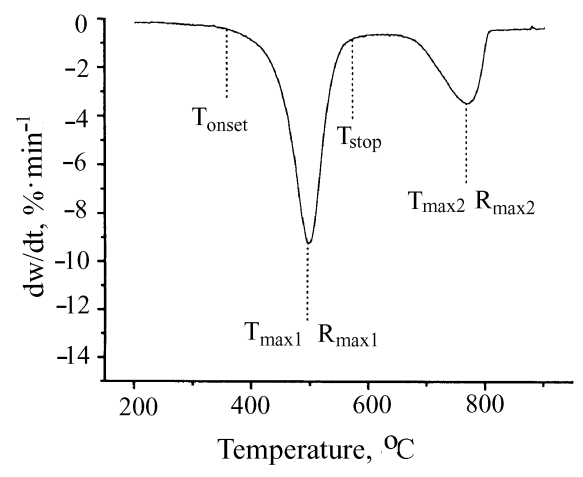

Fig.4. Symbols for Table 3.

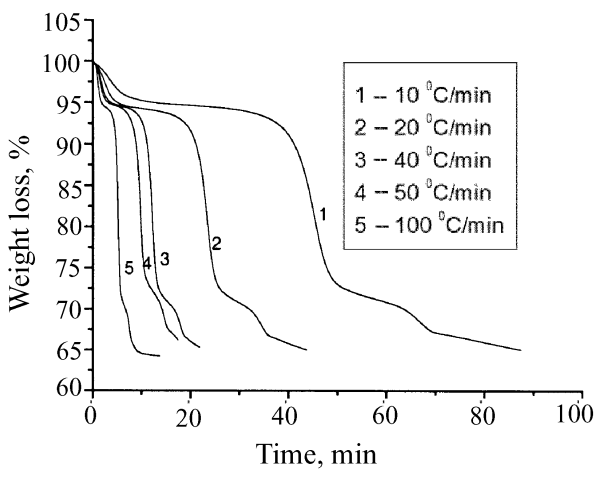

Fig.5. TG curves of the sample $\mathrm{S} 1$ at various heating rates.

\section{Kinetics of oil shale pyrolysis}

Non-isothermal kinetic study of weight loss under pyrolysis of oil shales is an extremely complex task because of the presence of numerous complex components and their parallel and consecutive reactions.

The extent of conversion or the fraction of pyrolysed material, $\alpha$, is defined by the expression 


$$
\alpha=\frac{w_{0}-w_{t}}{w_{0}-w_{f}}
$$

where $w_{0}$ is the initial weight, $w_{t}$ the weight at " $t$ " minutes, and $w_{f}$ the weight after complete pyrolysis.

Assuming that the reaction order is close to unity, kinetics of nonisothermal pyrolysis may be described by the following equation:

$$
\frac{d \alpha}{d t}=k f(\alpha)
$$

where $k$ (the rate constant) is given by the Arrhenius expression

$$
k=A \exp \left(-\frac{E}{R T}\right)
$$

where $A$ is the frequency factor $\left(\mathrm{s}^{-1}\right) ; E$ activation energy $\left(\mathrm{kJ} \cdot \mathrm{mol}^{-1}\right) ; R$ gas constant $\left(8.314 \cdot 10^{-3} \mathrm{~kJ} /(\mathrm{mol} \cdot \mathrm{K})\right)$; and $T$ absolute temperature $(\mathrm{K})$. According to the uniform kinetics of reaction, $f(\alpha)$ can be defined as $f(\alpha)=(1-\alpha)^{n}$, where $n$ is the reaction order. For a non-isothermal kinetic experiment with a linear heating rate of $\beta\left(\mathrm{K} \cdot \mathrm{min}^{-1}\right), \beta=d T / d t$.

Thus, the rate of kerogen decomposition is modified as

$$
\frac{d \alpha}{d t}=A \cdot \exp \left(-\frac{E}{R T}\right) \cdot(1-\alpha)^{n} .
$$

\section{Direct Arrhenius plot method}

Eq. (4) can be modified by introducing the heating rate as:

$$
\frac{1}{(1-\alpha)^{n}} \frac{d \alpha}{d T}=\frac{A}{\beta} \exp \left(-\frac{E}{R T}\right)
$$

In this method, Eq. (5) takes the logarithmic form giving:

$$
\ln \left[\frac{1}{(1-\alpha)^{n}} \frac{d \alpha}{d T}\right]=\ln \left(\frac{A}{\beta}\right)-\frac{E}{R T}
$$

Based on the experimental data of TG and DTG, $\alpha$ and $d \alpha / d T$ corresponding to instantaneous temperature can be obtained. Setting

$$
Y=\ln \left[\frac{1}{(1-\alpha)^{n}} \frac{d \alpha}{d T}\right], X=\frac{1}{T}
$$


the correct reaction order was determined by plotting $Y$ vs. $X$ for various values of $n$ (here $n=0.5,1,1.5,2$ ). Figure 6 shows the result. Decomposition of oil shale kerogen in terms of a first-order reaction appears to be a suitable assumption since the value of $n=1$ offers the best-fit regression line. According to Eq. (5), a plot of $Y$ vs. $X$ corresponds to a straight line with a slope of $(-E / R T)$, which can be used to evaluate the activation energy. The frequency factor can be determined from the intercept of $\ln (A / \beta)$. Table 4 presents the calculated kinetic parameters of pyrolysis of three oil shale samples in relation to heating rate.

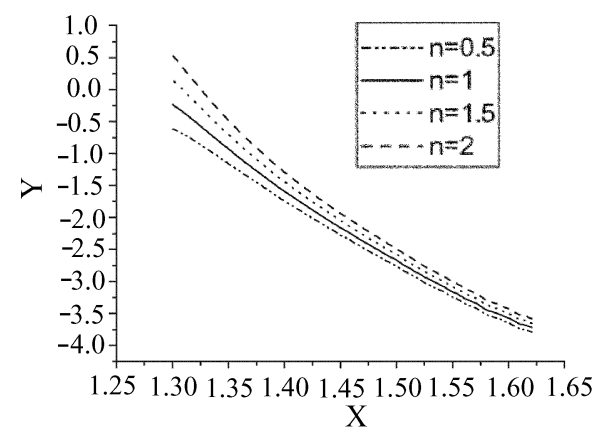

Fig.6. Y-X curves at different values of $n$.

Table 4. $\boldsymbol{E}$ and $\boldsymbol{A}$ of oil shale at different heating rates $(\boldsymbol{n}=\mathbf{1})$

\begin{tabular}{|c|c|c|c|c|}
\hline Sample & $\begin{array}{c}\text { Heating rate, } \\
\mathrm{K} \cdot \mathrm{min}^{-1}\end{array}$ & $\begin{array}{c}\text { Temperature, } \\
{ }^{\circ} \mathrm{C}\end{array}$ & $\begin{array}{c}E, \\
\mathrm{~kJ} \cdot \mathrm{mol}^{-1}\end{array}$ & $\begin{array}{c}A, \\
1 \cdot \min ^{-1}\end{array}$ \\
\hline S1 & $\begin{array}{c}\beta=10 \\
\beta=20 \\
\beta=40 \\
\beta=50 \\
\beta=100\end{array}$ & $\begin{array}{l}389-471 \\
393-485 \\
402-497 \\
403-496 \\
407-527\end{array}$ & $\begin{array}{l}137.67 \\
134.27 \\
135.85 \\
124.47 \\
130.34\end{array}$ & $\begin{array}{l}8.58 \mathrm{E}+09 \\
1.27 \mathrm{E}+10 \\
4.48 \mathrm{E}+10 \\
1.07 \mathrm{E}+10 \\
6.93 \mathrm{E}+10\end{array}$ \\
\hline S2 & $\begin{array}{c}\beta=10 \\
\beta=20 \\
\beta=40 \\
\beta=50 \\
\beta=100\end{array}$ & $\begin{array}{l}408-467 \\
400-482 \\
401-488 \\
411-496 \\
410-508\end{array}$ & $\begin{array}{l}148.78 \\
137.55 \\
129.67 \\
118.80 \\
127.84\end{array}$ & $\begin{array}{l}4.09 \mathrm{E}+10 \\
1.71 \mathrm{E}+10 \\
1.24 \mathrm{E}+10 \\
3.16 \mathrm{E}+09 \\
3.61 \mathrm{E}+10\end{array}$ \\
\hline S3 & $\begin{array}{l}\beta=10 \\
\beta=20 \\
\beta=40 \\
\beta=50 \\
\beta=100\end{array}$ & $\begin{array}{l}389-468 \\
393-467 \\
371-486 \\
384-497 \\
370-509\end{array}$ & $\begin{array}{c}113.36 \\
105.44 \\
103.75 \\
110.35 \\
99.49\end{array}$ & $\begin{array}{l}8.59 \mathrm{E}+07 \\
6.33 \mathrm{E}+07 \\
1.42 \mathrm{E}+08 \\
6.42 \mathrm{E}+08 \\
3.14 \mathrm{E}+08\end{array}$ \\
\hline
\end{tabular}




\section{Integral method}

Coats and Redfern developed an integral method, which can be applied to TG/DTG data, assuming the reaction order. The correct order is presumed to lead to the best linear plot. The form of the equations which is used for analysis is [12]

$$
\begin{gathered}
\ln \left\{\frac{1-(1-\alpha)^{1-n}}{T^{2}(1-n)}\right\}=\ln \left\{\frac{A R}{\beta E}\left[1-\frac{2 R T}{E}\right]\right\}-\frac{E}{R T} \quad n \neq 1 \\
\ln \left[\frac{-\ln (1-\alpha)}{T^{2}}\right]=\ln \left\{\frac{A R}{\beta E}\left[1-\frac{2 R T}{E}\right]\right\}-\frac{E}{R T} \quad n=1
\end{gathered}
$$

Due to $2 R T=E$, Eq. (7) and Eq. (8) can be further simplified into:

$$
\begin{aligned}
& \ln \left\{\frac{1-(1-\alpha)^{1-n}}{T^{2}(1-n)}\right\}=\ln \left(\frac{A R}{\beta E}\right)-\frac{E}{R T} \quad n \neq 1 \\
& \ln \left[\frac{-\ln (1-\alpha)}{T^{2}}\right]=\ln \left(\frac{A R}{\beta E}\right)-\frac{E}{R T} \quad n=1
\end{aligned}
$$

Therefore, a plot of the left side of Eq. (9) and Eq. (10) versus $1 / T$ at different orders of reaction $(n=0.5 ; 1 ; 1.5 ; 2)$ will give straight lines for the correct value of $n$. Setting the left side of Eq. (9) and Eq. (10) as $Y, 1 / T$ is $X$. Figure 7 shows the result. The value $n=1$ offers the best-fit regression line. So decomposition of oil shale is the first-order reaction. Activation energy $(E)$ can be calculated from the slope, the frequency factor can be determined from the intercept. Table 5 presents the kinetic parameters of three oil shale samples in relation to heating rate.

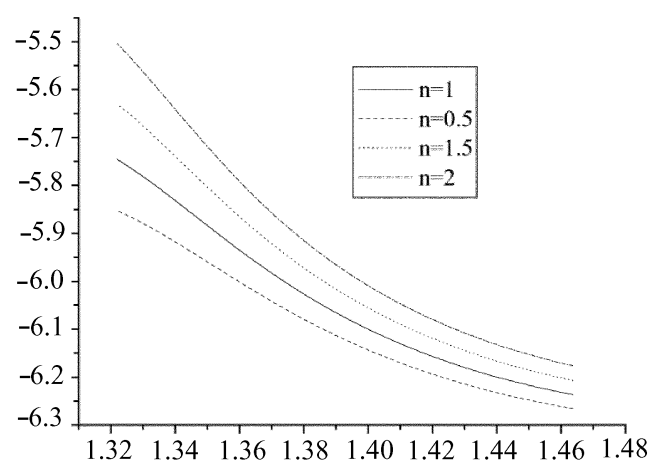

Fig.7. $Y$-X curves at different values of $n$. 
Table 5. Kinetic parameters of oil shale pyrolysis

\begin{tabular}{|c|c|c|c|c|}
\hline Sample & $\begin{array}{l}\text { Heating rate, } \\
\mathrm{K} \cdot \mathrm{min}^{-1}\end{array}$ & $\begin{array}{c}\text { Temperature, } \\
{ }^{\circ} \mathrm{C}\end{array}$ & $\begin{array}{c}E, \\
\mathrm{~kJ} \cdot \mathrm{mol}^{-1}\end{array}$ & $\underset{1 \cdot \mathrm{min}^{-1}}{A,}$ \\
\hline $\mathrm{S} 2$ & $\begin{array}{c}\beta=10 \\
\beta=20 \\
\beta=40 \\
\beta=50 \\
\beta=100 \\
\beta \beta=10 \\
\beta=20 \\
\beta=40 \\
\beta=50 \\
\beta=100 \\
-\beta=10 \\
\beta=20 \\
\beta=40 \\
\beta=50 \\
\beta=100\end{array}$ & $\begin{array}{r}426-502 \\
449-513 \\
451-526 \\
469-523 \\
471-511 \\
-440-495 \\
452-505 \\
459-520 \\
472-520 \\
484-537 \\
-431-482 \\
446-501 \\
462-516 \\
466-526 \\
472-524\end{array}$ & $\begin{array}{r}80.63 \\
84.18 \\
84.26 \\
81.69 \\
-84.66 \\
76.59 \\
78.28 \\
80.82 \\
65.81 \\
-77.33 \\
60.14 \\
47.94 \\
62.09 \\
62.19 \\
61.01\end{array}$ & $\begin{array}{l}1.52 \mathrm{E}+05 \\
2.32 \mathrm{E}+05 \\
5.79 \mathrm{E}+05 \\
1.10 \mathrm{E}+06 \\
2.01 \mathrm{E}+06 \\
3.41 \mathrm{E}+05 \\
6.64 \mathrm{E}+05 \\
1.22 \mathrm{E}+06 \\
1.28 \mathrm{E}+07 \\
6.67 \mathrm{E}+06 \\
4.15 \mathrm{E}+06 \\
5.57 \mathrm{E}+07 \\
1.87 \mathrm{E}+07 \\
2.42 \mathrm{E}+07 \\
7.34 \mathrm{E}+07\end{array}$ \\
\hline
\end{tabular}

From the data in Table 4 and Table 5, it was found that the value of activation energy only slightly depends on heating rate. However, the value calculated by the direct Arrhenius plot method is higher than that calculated by the integral method. Some other researchers have found that activation energy values are influenced by numerous factors, such as the type of oil shale, temperature interval of pyrolysis, method of mathematical analysis, pyrolysis techniques, and others. So the literature offers a wide range of value of activation energy. Besides, oil shale is a matter of complex heterogeneous nature, especially its kerogen; hence, it would be difficult to achieve same experimental results, even for nominally the same sample (e.g., in this study and in order to reduce the margin of error and so produce more reliable data, the key tests were repeated). Therefore, the same experimental technique, including sample preparation procedure, analysis method adopted, and the kinetic model for the analysis, should be employed in order to enable a reasonable comparison to be achieved.

\section{Conclusions}

In this research, an experimental study on thermal decomposition characteristics of Huadian oil shale samples is presented. The following conclusions were drawn from the research conducted:

1. The decomposition process of Huadian oil shale involves three stages. The second stage $\left(200-600{ }^{\circ} \mathrm{C}\right)$ is the main weight loss stage, attributed to decomposition of the hydrocarbonaceous material.

2. There is a shift in the maximum rate of weight loss to higher temperature with increasing heating rate. 
3. Experimental and kinetic analysis data enabled to establish that decomposition of Huadian oil shale samples is a first-order reaction. The values of activation energy did not depend on the mathematical method used. The influence of heating rate on activation energy was not elucidated in this research.

\section{Acknowledgements}

The authors are grateful for financial support from the Ministry of Science and Technology of the People's Republic of China (2004BA907A25) and from the Department of Education of Jilin Province.

\section{REFERENCES}

1. Kök, M. V., Pamir, M R. ASTM kinetics of oil shales // J. Therm. Anal. 1998. Vol. 53, No. 2. P. 567-575.

2. Barkia, H., Belkbir, L., Jayaweera, S. A. A. Thermal analysis studies of oil shale residual carbon // J. Therm. Anal. Cal. 2004. Vol. 76, No. 2. P. 615-622.

3. Qian, J. L. Wang, J. Q., Li, S. Y. Oil shale development in China // Oil Shale. 2003. Vol. 20, No. 3. P. 356-359.

4. Williams, P. T., Ahmad, N. Investigation of oil-shale pyrolysis processing condition using thermogravimetric analysis // Applied Energy. 2000. Vol. 66, No. 2. P. 113-133.

5. Wang, Q., Bai, J. R., Sun, B. Z., Sun, J. Comprehensive utilization strategy of Huandian oil shale // Oil Shale. 2005. Vol. 22, No. 3. P. 305-316.

6. Jaber, J. O., Probert, S. D. Pyrolysis and gasification kinetics of Jordanian oilshales // Applied Energy. 1999. Vol. 63, No. 4. P. 269-286.

7. Williams, P. T., Ahmad, N. Influence of process conditions on the pyrolysis of Pakistan oil shales // Fuel. 1999. Vol. 78, No. 6. P. 653-662.

8. Jaber, J. O., Probert, S. D. Non-isothermal thermogravimetry and decomposition kinetics of two Jordanian oil shales under different processing conditions // Fuel Process. Technol. 2000. Vol. 63, No. 1. P. 57-70.

9. Doğan, Ö. M., Uysal, B. Z. Non-isothermal pyrolysis kinetics of three Turkish oil shales // Fuel. 1996. Vol. 75, No. 12. P. 1424-1428.

10. Thakur, D. S., Nuttal, H.E. Kinetics of pyrolysis Moroccon oil shale by thermogravimetry // Ind. Eng. Chem. Res. 1987. Vol. 26, No. 7. P. 1351-1356.

11. Williams P. F. V. Thermogravimetry and decomposition kinetics of British Kimmeridge Clay oil shale // Fuel. 1985. Vol. 64, No. 4. P. 540-545.

12. Khraisha, Y.H., Shabib, I., M. Thermal analysis of shale oil using thermogravimetry and differential scanning calorimetry // Energy Convers. Mngm. 2002. Vol. 43, No. 2. P. 229-239

Presented by Qian Jialin

Received January 3, 2006 